\title{
Analisis Implementasi Sistem Informasi Keuangan, Kompetensi Pegawai dan Evaluasi Manajemen Terhadap Efektifitas Pengelolaan Keuangan Pada Unit Program Belajar Jarak Jauh Universitas Terbuka Seluruh Indonesia
}

\section{Irwandi}

Universitas Terbuka, Indonesia

Email: irwandy.skom@gmail.com

\section{A R T I C L E I N F O}

DOI: 10.32832/jm-uika.v10i1.1893

Article history:

Received:

27 Mai 2019

Accepted:

21 Juni 2019

Available online:

30 Juni 2019

Keywords:

Impelmentation, Competence, Evaluation, Effectiveness, Partial Least Square

\section{A B S T R A C T}

Financial management is one of the factors that determine the achievement of organizational goals. In order for financial management (budget) to run in an orderly and accountable financial information system. To further optimize the work of information systems so that effectiveness can be achieved requires implementation activities, employee competencies and management evaluation of the financial information system.

This study aims to analyze: 1). Analyzing the influence of the implementation of financial information systems on the effectiveness of financial management, 2). Analyzing the influence of employee competency on financial management effectiveness 3). Analyze the influence of management evaluations on the effectiveness of financial management in the Open University Distance Learning Program Unit throughout Indonesia.The study was conducted using quantitative descriptive method, the research sampling used purposive sampling non probability with a total sample of 117 respondents. The data analysis technique used is regression analysis using Partial Least Square (PLS). The results showed that the implementation of financial information systems had a significant effect on the effectiveness of financial management, employee competence, financial management and management evaluation also financial management. Determination coefficient value obtained is $64.80 \%$, it can be concluded that the implementation of financial information systems, employee competencies and management evaluation of effective financial management. 


\section{Pendahuluan}

Mencerdaskan kehidupan bangsa merupakan salah satu tujuan yang hendak dicapai oleh pemerintah Indonesia. Usaha untuk mencapai masyarakat yang cerdas dan berkualitas harus dimulai sedini mungkin melalui kegiatan pendidikan. Pemerintah mencanangkan setiap warga negara wajib belajar 12 tahun. Selain itu memenuhi kebutuhan pendidikan tinggi Pemerintah telah menyediakan sekolah tinggi bagi masyarakat dengan mendirikan Universitas Terbuka. Pendirian perguruan tinggi lebih diperuntukkan untuk masyarakat yang sulit memiliki waktu luang untuk kegiatan belajar atau perkuliahan karena kendala pekerjaan, jarak rumah dan lain sebagainya. Oleh sebab itu sistem pembelajaran perguruan tinggi ini menggunakan sistem belajar jarak jauh.

Sebagai sebuah lembaga yang memiliki kegiatan di bidang pendidikan sudah seharusnya universitas terbuka dikelola dengan sebaik mungkin untuk menjamin keberlangsungan hidupnya. Salah satu kegiatan yang perlu dikelola secara efektif dan efisien adalah pengelolaan keuangan. Hal ini perlu dilakukan karena pengelolaan keuangan berkaitan dengan target (anggaran) dan realisasi (pendapatan) yang diharapkan. Dengan demikian pengelolaan keuangan merupakan salah satu faktor yang menentukan keberhasilan pencapaian tujuan organisasi. Agar pengelolaan keuangan (anggaran) berjalan secara tertib dan akuntabel diperlukan sistem informasi keuangan. Untuk lebih mengoptimalkan kerja sistem informasi agar efektifitas dapat tercapai dibutuhkan kegiatan implementasi, kompetensi pegawai dan evaluasi manajemen terhadap sistem informasi keuangan tersebut.

Oleh karena itu penelitian ini bertujuan untuk menganalisa pengaruh implementasi sistem informasi keuangan, kompetensi pegawai dan evaluasi manajemen terhadap efektifitas pengelolaan keuangan.

\section{Tinjauan Pustaka}

Pengelolaan Keuangan

Perencanaan anggaran, pelaksanaan anggaran, penatausahaan, pertanggungjawaban dan pemeriksaan laporan keuangan adalah cakupan dari Pengelolaan Keuangan. Kebijakan pengelolaan keuangan adalah kebijakan yang harus dijalankan, dan kebijakan yang sifatnya regulasi bersifat top down, bahkan bersifat memaksa, karena kebijakan ini dijadikan pedoman dalam pengelolaan keuangan tingkat apapun. Udoji dalam Irfan (2006:h.152) menyatakan bahwa pelaksanaan kebijakan (tata kerja) adalah sesuatu yang paling penting, bahkan mungkin yang jauh lebih penting dari pada pembuatan kebijakan. Kebijakan-kebijakan hanya akan sekedar berupa impian atau rencana bagus yang tersimpan rapi dalam arsip kalau tidak diimplementasikan.

\section{Efektifitas Pengelolaan Keuangan}

Menurut Devas, Tangkilisan (2004:h.242) bahwa efektifitas adalah hubungan antara output dan tujuan dan dapat juga dikatakan merupakan ukuran 
seberapa jauh tingkat output dengan kebijakan dan sistem yang diterapkan suatu institusi. Manopo (2015:h.6) mengungkapkan bahwa ukuran kemampuan dalam mencapai tujuan tertentu adalah efektifitas. Dalam mewujudkan efektivitas pengelolaan keuangan maka pengelolaan keuangan diimplementasikan dengan menggunakan prinsipprinsip pengelolaan keuangan yang meliputi : 1). Prinsip taat asas, 2). Taat aturan perundangan, 3). Ffektifitas, 4). Efisiensi, 5). Ekonomis, 6). Transparan, 7). Tanggungjawab, 8). Adil, 9). Patutan dan 10). Bermanfaat.

Menurut Bandary (2011:h.82) semua aktifitas keuangan yang diproses oleh suatu entitas pelaporan tersusun pada 1 periode sebagai informasi yang relevan atas kondisi keuangan akan mencerminkan pengelolaan keuangan yang baik.

\section{Sistem Informasi Akuntansi}

Menurut Bordnar dan Hopwood (2006:h.3) Proses data diubah menjadi informasi adalah Sistem Informasi. Data masuk atau data keluar yang dihasilkan disimpan, pada saat dibutuhkan data diolah kembali dengan input yang baru, disajikan menjadi informasi yang dapat digunakan.

Menurut Onaolapo dan Odetayo (2012:h.183) Data lama dan baru (update) pada proses ekonomi yang menggunakan sistem komputer menghasilkan informasi akuntansi keuangan adalah Sistem Informasi Akuntansi. Sedangkan menurut Soudani (2012:h.136) Informasi yang dimasukan pada sistem berbasis IT, diolah menjadi informasi keuangan yang berkualitas menjadi salah satu keunggulan organisasi adalah Sistem Informasi Akuntansi.
Implementasi

Pengertian implementasi menurut Hazirwan (2008:h.138) adalah pelaksanaan kegiatan yang berupa tahapan yang menghubungkan antara rencana dengan tujuan yang telah ditetapkan. Dengan kata lain implementasi merupakan proses penerjemahan kebijakan (policy statement) ke dalam aksi kebijakan (policy acion). Kemudian Agustiono (2012:h.139) menyatakan bahwa implementasi sistem informasi adalah suatu proses yang dinamis, dimana pelaksana sistem melakukan suatu aktivitas sehingga akhirnya akan mendapatkan suatu hasil yang sesuai dengan tujuan atau sasaran sistem tersebut.

Bertolak pada teori di atas mengandung makna bahwa ketika kebijakan sudah dibuat maka tugas selanjutnya adalah mengorganisasikan, melaksanakan kepemimpinan untuk memimpin pelaksanaan, dan melakukan pengendalian pelaksanaan tersebut. Dengan demikian variabel kunci atau indikator dari implementasi adalah 1) mengorganisasikan pelaksanaan kebijakan, 2) melaksanakan kepemimpinan untuk memimpin pelaksanaan kebijakan (leading) dan 3) melaksanakan pengendalian pelaksanaan kebijakan (controlling).

\section{Kompetensi}

Menurut Gibson, dkk. (2009:h.123), kompetensi adalah suatu kondisi seseorang yang mampu menyelesaikan tugasnya dengan baik. Kemampuan menunjukkan potensi orang untuk melaksanakan tugas. Kompetensi pegawai merupakan bentuk dari pengetahuan dan keterampilan yang dimiliki, tidak semua pegawai memiliki kemampuan untuk bekerja 
dengan baik meskipun sudah diberi motivasi.

Wibowo (2013:h.324) berpendapat kemampuan kerja individu mencakup aspek pengetahuan, keterampilan dan sikap kerja yang sesuai dengan standar adalah Kompetensi pegawai. Kompetensi pada hubungan pekerjaan dapat dikatakan sebagai suatu keadaan pada seseorang yang secara penuh kesungguhan, berdaya guna melaksanakan pekerjaan sehingga menghasilkan sesuatu yang optimal. Kompetensi menunjukkan kematangan yang berkaitan pula dengan pengetahuan dan keterampilan. Kompetensi bersifat konsisten dan sesuai dengan standar kinerja yang disyaratkan dalam suatu pekerjaan.

Menurut Robbins and Judges (2009:h.274) untuk mengukur kompetensi dapat menggunakan beberapa indikator antara lain : 1) kesanggupan kerja, yaitu suatu kondisi di mana seorang karyawan merasa mampu menyelesaikan pekerjaan yang diberikan kepadanya, 2) pendidikan yaitu kegiatan untuk meningkatkan pengetahuan seseorang termasuk di dalamnya peningkatan penugasan teori dan keterampilan memutuskan terhadap persoalan yang menyangkut kegiatan mencapai sebuah tujuan dan 3) masa kerja (pengalaman) yaitu waktu yang dibutuhkan oleh seorang karyawan dalam bekerja pada sebuah perusahaan atau organisasi.

\section{Evaluasi}

Evaluasi sistem informasi bertujuan menilai kemampuan teknis implementasi sistem informasi, operasional sistem dan pemanfaatan sistem untuk mendapatkan hasil dalam mengambil tindakan selanjutnya untuk perencanaan memperbaiki kinerja suatu sistem. (Hakam,2016:h.113). Evaluasi merupakan bagian dari pengendalian internal, karena evaluasi merupakan bentuk pengendalian setelah kegiatan selesai dilaksanakan.

Prabowo (2013:h.91) menyatakan sub komponen dari aktivitas pengendalian yang berhubungan dengan pelaporan keuangan adalah perancangan yang memadai dan pengunaan dokumen dan catatan bernomor, pemisahan tugas, otorisasi yang memadai atas transaksi, pemeriksaan independen atas kinerja dan penilaian yang sesuai atas jumlah yang dicatat.

Evaluasi Manajemen terhadap sistem informasi keuangan perlu dilakukan untuk melihat tingkat kesuksesan sistem tersebut dalam meningkatkan kinerja. Oleh sebab itu untuk mengukur evaluasi dapat digunakan proksi model kesuksesan sistem informasi yang dikembangkan oleh DeLone dan McLean (1992:h.60). Dalam model ini evaluasi sistem informasi keuangan dapat dilakukan dengan mengukur beberapa indikator antara lain kualitas sistem (system quality), kualitas informasi (information quality), kepuasan pemakai (user statisfaction), penggunaan (use), dampak individu (individual impact), dan dampak organisasi (organizational impact).

\section{Kerangka Pemikiran}

Untuk menyelenggarakan pelaksanaan anggaran keuangan yang tertib dan akuntabel Unit Program Belajar Jarak Jauh Universitas Terbuka mengembangkan dan memanfaatkan kemajuan teknologi informasi untuk meningkatkan kemampuan mengelola keuangannya. Efektifitas pengelolaan keuangan dapat dipengaruhi oleh 
implementasi sistem tersebut, kompetensi pegawai dan evaluasi manajamen. Untuk jelasnya penelitian ini digambarkan sebagai berikut:

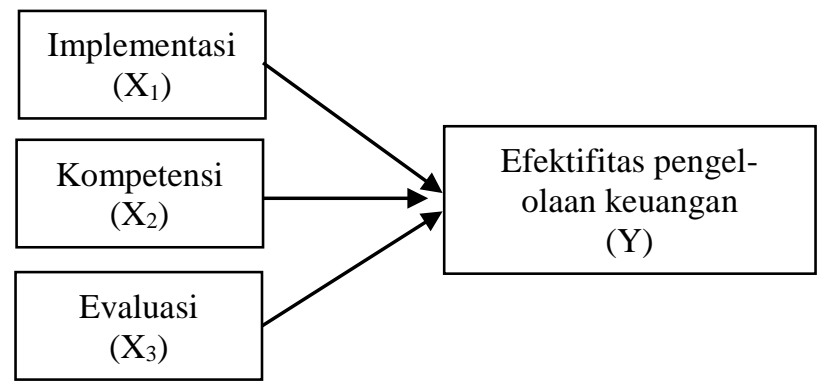

\section{Metode Penelitian}

Tempat dan Waktu Penelitian

Penelitian dilakukan di Badan Layanan Umum Pada Unit Program Belajar Jarak Jauh Universitas Terbuka Seluruh Indonesia dan waktu penelitian selama empat bulan mulai bulan Januari sampai dengan April 2019

\section{Jenis Penelitian}

Jenis penelitian ini adalah studi empirik dengan pendekatan metode deskriptif kuantitatif

\section{Populasi dan Sampel}

Populasi penelitian ini adalah pegawai negeri sipil (PNS) pada UPBJJ Universitas Terbuka dari 39 kantor unit di seluruh Indonesia. Sampel diambil menggunakan teknik purposive sampling non probability, yaitu hanya peserta Rakernas UPBJJ-UT masing-masing unit 3 (tiga) orang dengan kriteria : 1). Pejabat UPBJJ, 2). PNS UT, 3). User Aplikasi MANISKU sehingga jumlah sampel sebanyak 117 orang.
Teknik Pengumpulan data

Pengumpulan data dilakukan menggunakan teknik penelitian lapangan yakni : wawancara, observasi, kuesioner dan penelitian kepustakaan.

Teknik Analisis

Analisis data dilakukan dengan tiga tahap, yaitu: 1) uji validitas dan reliabilitas, 2) analisis deskriptif menggunakan rata-rata tertimbang dan 3) analisis regresi menggunakan Partial Least Square (PLS).

Penelitian yang Relevan

a. Analisis Kesuksesan Implementasi Sistem Informasi Manajemen Keuangan Daerah Pemerintah Kabupaten Sukoharjo, Mia Triandhini (2018), Thesis, Universitas Muhammadiyah Surakarta

Hasil penelitian menyimpulkan bahwa kualitas sistem dan kualitas informasi berpengaruh terhadap kegunaan yang dirasakan user dan kegunaan yang dirasakn berpengaruh terhadap kepuasan user (pengguna)

b. Evaluasi Sistem Informasi Manajemen Di Bagian Rawat Jalan RSUD DR Moewadi Surakarta, Anggun Niantyasari (2018), Thesis, Universitas Muhammadiyah Surakarta

Hasil penelitian menyimpulkan bahwa tampilan, fungsi, kinerja dan kualitas dari sistem informasi dibagian rawat jalan berpengaruh positif terhadap kepuasan pengguna sistem informasi

c. Evaluasi Efisiensi dan Efektifitas Pengelolaan Keuangan Daerah Pada Badan Pengelola Keuangan dan Barang Milik Daerah (BKPBMD) Kota Bitung, Mega F, Syahril dan Ventje Ilat (2016), Fakultas Ekonomi dan Bisnis Universitas Sam Ratulangi Manado 
Hasil penelitian menyimpulkan tingkat efektivitas pengelolaan keuangan daerah BPKBMD rata-rata di atas $100 \%$ tetapi pengelolaan keuangannya masih dikategorikan kurang efisien

\section{d. Pengaruh Kompetensi Pengelola Keuangan} dan Sistem Akuntansi Keuangan Daerah Terhadap Kualitas Laporan Keuangan, Lia Hanifa, Andi Basru Wawo dan Husin (2016), Jurnal Progres Ekonomi Pembangunan, Vol 1, nomor 2. 2016

Hasil penelitian menyimpulkan kualitas laporan keuangan daerah dipengaruhi oleh sistem akuntansi keuangan daerah serta kompentensi pengelola keuangannya.

\section{e. Pengaruh Kompetensi Pejabat Pengelola Keuangan, Regulasi dan Pengawasan Keuangan Daerah Terhadap Kualitas Laporan Keuangan SKPD di Lingkungan Pemerintah Kabupaten Simeuleu, Kuasa, Nadisyah dan Syukri Abdullah (2016), Jurnal Magister Akuntansi Pasca Sarjana Universitas Syiah Kuala}

Hasil penelitian menyimpulkan bahwa kompetensi pejabat pengelola keuangan, regulasi dan pengawasan keuangan daerah berpengaruh terhadap kualitas laporan keuangan

\section{Hasil}

\section{a. Analisis Deskripsi}

Hasil tanggapan responden terhadap implementasi sistem informasi keuangan, kompetensi pegawai, evaluasi manajemen dan efektifitas pengelolaan keuangan ditunjukkan:

Tabel 1. Deskripsi Tanggapan Responden

\begin{tabular}{|c|c|c|}
\hline Variabel & $\begin{array}{c}\text { Angka } \\
\text { penafsiran }\end{array}$ & Kriteria \\
\hline Implementasi sistem & 3,52 & baik \\
\hline
\end{tabular}

\begin{tabular}{|l|c|c|}
\hline informasi keuangan & & \\
\hline Kompetensi pegawai & 3,42 & baik \\
\hline Evaluasi manajemen & 3,50 & baik \\
\hline $\begin{array}{l}\text { Efektifitas pengelolaan } \\
\text { keuangan }\end{array}$ & 3,52 & baik \\
\hline
\end{tabular}

Analisis di atas menunjukkan bahwa tanggapan responden terhadap implementasi sistem informasi keuangan, kompetensi pegawai, evaluasi manajemen dan efektifitas pengelolaan keuangan adalah baik.

\section{b. Analisis Regresi}

Hasil analisis menggunakan PLS diperoleh model pengukuran (outer model) sebagai berikut:

$$
\begin{aligned}
\mathrm{X}_{1}= & 0,584 \mathrm{x}_{1.1}-0,012 \mathrm{x}_{1.2}+0,174 \mathrm{x}_{1.3}+0,159 \mathrm{x}_{1.4} \\
& +0,161 \mathrm{x}_{1.5}-0,129 \mathrm{x}_{1.6}+0,329 \mathrm{x}_{1.7}+\mathrm{e} \\
\mathrm{X}_{2}= & 0,416 \mathrm{x}_{2.1}+0,233 \mathrm{x}_{2.2}+0,172 \mathrm{x}_{2.3}+0,228 \mathrm{x}_{2.4} \\
& +0,236 \mathrm{x}_{2.5}+0,104 \mathrm{x}_{2.6}+\mathrm{e} \\
\mathrm{X}_{3}= & 0,782 \mathrm{x}_{3.1}-0,164 \mathrm{x}_{3.2}-0,078 \mathrm{x}_{3.3}+0,348 \mathrm{x}_{3.4}+ \\
& 0,060 \mathrm{x}_{3.5}+0,091 \mathrm{x}_{3.6}+0,243 \mathrm{x}_{3.7}+0,053 \mathrm{x}_{3.8}+ \\
\mathrm{Y}= & \mathrm{e} \\
& 0,593 \mathrm{y}_{1}+0,133 \mathrm{y}_{2}+0,063 \mathrm{y}_{3}-0,024 \mathrm{y}_{4}+ \\
& 0,341 \mathrm{y}_{5}+0,044 \mathrm{y}_{6}+0,086 \mathrm{y}_{7}+0,260 \mathrm{y}_{8}+\mathrm{e}
\end{aligned}
$$

Pengujian Multikolinearitas

Dari hasil analisis diketahui nilai VIF variabel implementasi $\left(\mathrm{X}_{1}\right)$ sebesar 2,045, variabel kompetensi $\left(\mathrm{X}_{2}\right)$ 2,357 dan variabel evaluasi $\left(\mathrm{X}_{3}\right)$ 1,586. Karena nilai VIF variabel eksogen lebih kecil dari 10, maka dapat dikatakan tidak terjadi multikolinearitas dan selanjutnya dilakukan pengujian outer weight masing-masing variabel.

Pengujian Outer Weights dan Outer Loadings

Hasil pengujian menunjukkan nilai t-statistik outer weights indikator yang lebih besar dari 1,984 adalah indikator $\mathrm{x}_{1.1}, \mathrm{x}_{1.7}, \mathrm{x}_{2.1}, \mathrm{x}_{3.1}, \mathrm{x}_{3.4}, \mathrm{y}_{1}$ dan $\mathrm{y}_{5}$. Dengan demikian ini menunjukkan semua indikator memiliki kontribusi terhadap variabel latennya. Kemudian indikator yang tidak signifikan dilakukan 
perhitungan outer loadings dan dari hasil pengujian diketahui bahwa indikator yang memiliki nilai outer loadings di bawah 0,5 adalah indikator $\mathrm{x}_{1.6}, \mathrm{x}_{3.2}, \mathrm{x}_{3.3}$, $\mathrm{x}_{3.5}, \mathrm{x}_{3.6}, \mathrm{x}_{3.7}, \mathrm{y}_{3}, \mathrm{y}_{4}, \mathrm{y}_{6}$ dan $\mathrm{y}_{8}$, dengan demikian indikator-indikator ini dibuang.

Setelah dilakukan analisis data kembali diperoleh hasil:

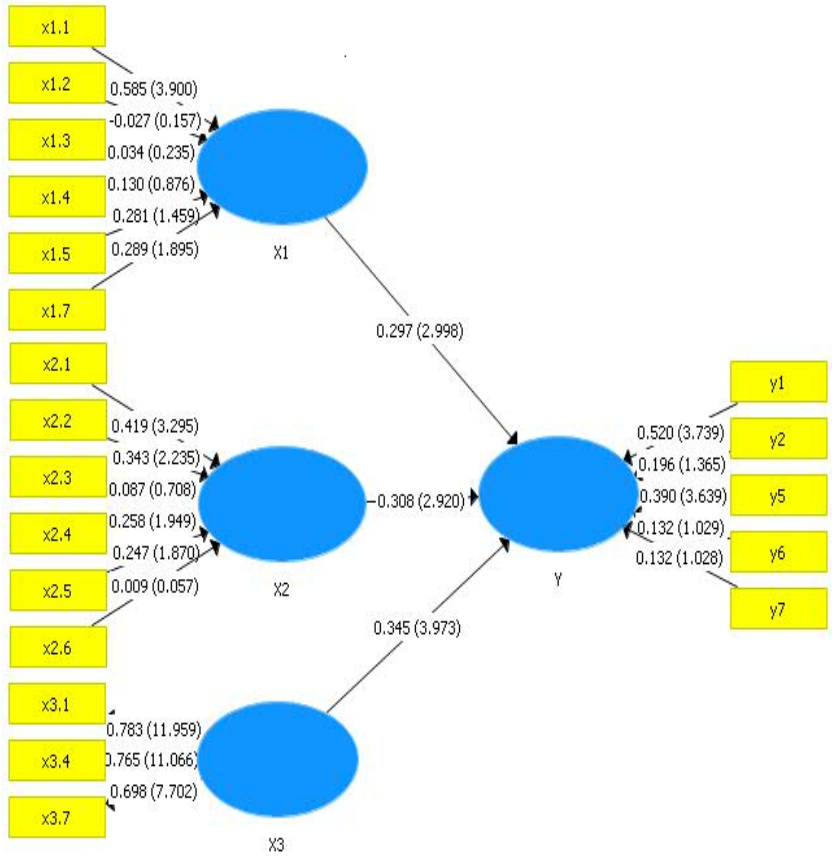

Gambar 1.

Diagram Model Pengukuran (Outer Model) dan Model Struktural

Dari diagram tersebut diperoleh persamaan : $\mathrm{Y}=0,297 \mathrm{X}_{1}+0,308 \mathrm{X}_{2}+0,345 \mathrm{X}_{3}$

Pengujian Hipotesis Pengujian model struktural ini ddapat dijelaskan dengan tabel berikut:

Tabel 2. Hasil Perhitungan

\begin{tabular}{|l|r|r|r|}
\hline \multicolumn{1}{|c|}{ Hubungan variabel } & $\begin{array}{c}\text { Estimasi } \\
\text { Koefisien } \\
\text { Jalur }\end{array}$ & $\begin{array}{c}\text { t- } \\
\text { statistik }\end{array}$ & $\begin{array}{c}\boldsymbol{p} \\
\text { value }\end{array}$ \\
\hline Implementasi $\rightarrow$ efektifitas & 0,297 & 2,998 & 0,003 \\
\hline Kompetensi $\rightarrow$ efektifitas & 0,308 & 2,920 & 0,004 \\
\hline Evaluasi $\rightarrow$ efektifitas & 0,345 & 3,973 & 0,000 \\
\hline
\end{tabular}

Hasil pengujian menunjukkan:

- Nilai t-hitung implementasi sistem informasi keuangan 2,998 dengan nilai p-value 0,003 sehingga dapat dikatakan implementasi sistem informasi keuangan berpengaruh signifikan terhadap efektifitas pengelolaan keuangan

- Nilai t-hitung kompetensi pegawai 2,920 dengan nilai p-value 0,004 sehingga dapat dikatakan kompetensi pegawai berpengaruh signifikan terhadap efektifitas pengelolaan keuangan

- Nilai t-hitung evaluasi manajamen 3,973 dengan nilai p-value 0,000 sehingga dapat dikatakan evaluasi manajemen berpengaruh signifikan terhadap efektifitas pengelolaan keuangan

\section{Effect Size}

Pengujian nilai $\mathrm{f}^{2}$ (effect size) diketahui bahwa pengaruh implementasi manajemen terhadap efektifitas pengelolaan keuangan $\left(\mathrm{X}_{1} \rightarrow \mathrm{Y}\right)$ sebesar 0,129 yang berarti pengaruhnya termasuk lemah. Kemudian pengaruh kompetensi pegawai terhadap efektifitas pengelolaan keuangan $\left(\mathrm{X}_{2} \rightarrow \mathrm{Y}\right)$ sebesar 0,118 yang termasuk dalam kategori lemah, sedangkan pengaruh evaluasi manajemen terhadap efektifitas pengelolaan keuangan $\left(\mathrm{X}_{3} \rightarrow \mathrm{Y}\right)$ sebesar 0,221 yang termasuk dalam kategori medium

Determinasi

Nilai koefisien determinasi implementasi sistem informasi keuangan, kompetensi pegawai dan evaluasi manajemen secara simultan 64,80\% yang menginterpretasikan bahwa ketiga variabel eksogen tersebut secara simultan memberikan kontribusi 
terhadap perubahan efektifitas pengelolaan keuangan sebesar $64,80 \%$, dan sisanya $(35,20 \%)$ dikontribusi atau ditentukan oleh variabel lain yang tidak diteliti dalam penelitian ini. Nilai determinasi ini juga menginterpretasikan bahwa model sturktural ini termasuk dalam kategori mendekati baik

\section{Penutup}

Masukan dan saran atas hasil penelitian ini antara lain:

a. Perlunya dilakukan kegiatan pelatihan implementasi sistem informasi keuangan secara kontinyu.

b. Kompetesi pegawai yang sudah baik sebaiknya perlu dipertahankan bahkan lebih ditingkatkan lagi/

c. Perlunya melakukan kegiatan evaluasi secara intenstif terhadap sistem informasi keuangan yang diterapkan organisasi.

Kemudian implikasi penelitian diuraikan:

a. Implikasi teoritis

- Ketika kebijakan sudah dibuat, maka tugas selanjutnya adalah mengorganisasikan, melaksanakan kepemimpinan untuk memimpin pelaksanaan dan melakukan pengendalian pelaksanaan tersebut.

- Data yang disimpan merupakan suatu penegasan selama proses berlangsung, semua input yang masuk diolah menjadi keluaran semuanya.

- Kompetensi dalam hubungan pekerjaan adalah keadaan seseorang yang secara penuh kesungguhan, berguna dalam melakukan pekerjaan sehingga menghasilkan sesuatu yang optimal.

- Evaluasi sistem informasi bertujuan menilai kemampuan teknis implementasi sistem informasi, operasional sistem dan pemanfaatan sistem untuk mendapatkan hasil dalam mengambil tindakan selanjutnya untuk perencanaan memperbaiki kinerja suatu sistem.

- Efektivitas berhubungan dengan tingkat keberhasilan suatu kegiatan. Suatu kegiatan dikatakan efektif jika kegiatan tersebut memiliki pengaruh besar terhadap kemampuan penyediaan pelayanan yang merupakan target yang ditentukan.

b. Implikasi praktis

Hasil penelitian ini diharapkan dapat menjadi masukan bagi pemangku kebijakan dilingkungan Universitas Terbuka dalam menyusun kebijakan yang berkaitan dengan sistem informasi keuangan sehingga dapat meningkatkan kualitas pengelolaan keuangan UPBJJ-UT seluruh Indonesia.

\section{REFERENCES}

Agustiono. 2012. Implementasi Kebijakan Publik Model Van Meter dan Van Horn. Jakarta:Rajawali Press.

Al-eqab, M. and Adel, D. 2013. The Impact of IT Sophistications on the Perceived Usefulness of Accounting Information Characteristics among Jordanian Listed Companies. Journal of Bussiness and Social Science, 4(3), pp: 145155.

Gibson, J.L, Ivancevich, J.M and Donnelly. 2009. Organizations. New York : Richard Irwin.

Hakam, F. 2016. Analisis, Perancangan dan Evaluasi Sistem Informasi Kesehatan. Yogyakarta: Gosyen Publishing. 
Hanifa, Lia., Andi Basru W dan Husin. 2016. Pengaruh Kompetensi Pengelola Keuangan dan Sistem Akuntansi Keuangan Daerah Terhadap Kualitas Laporan Keuangan. Jurnal Progres Ekonomi Pembangunan, Vol 1, nomor 2. 2016.

Hazirwan. 2008. Implementasi Kebijakan Pembinaan dan Pengawasan (Binwas) Penyelenggaraan Pemerintahan Daerah (Tesis). PPS UGM Yogyakarta.

Irfan. 2006. Implementasi Kebijakan Pengembangan Pariwisata di Kabupaten Donggala (Studi pada Dinas Kebudayaan dan Pariwisata Kabupaten Donggala) (Tesis). Palu:PPS UNTAD.

Kuasa, Nadirsyah dan Syukriy A. 2016. Pengaruh Kompetensi Pejabat Pengelola Keuangan, Regulasi dan Pengawasan Keuangan Daerah Terhadap Kualitas Laporan Keuangan SKPD di Lingkungan Pemerintah. Aceh. Jurnal Magister Akuntansi Pasca Sarjana Universitas Syiah Kuala.

Niantyasari, Anggun. 2018. Evaluasi Sistem Informasi Manajemen DI Bagian Rawat Jalan RSUD DR Moewardi Surakarta. Pasca Sarjana Universitas Muhammadiyah Surakarta.

Onaolapo, A.A and Odetayo T.A. 2012. Effect of Accounting Information System on Organisational Effectiveness : A Case Study of Selected Construction Companies in Ibadan, Nigeria. American Journal of Business and Management. Vol. 1, No. 4, 2012, 183-189.

Robbins, S.P and Judges. 2009. Teori dan
Pengukuran Pengetahuan, Sikap dan Perilaku Manusia. Yogyakarta : Nuha Medika.

Soudani, Siamak N,.H. 2012. The Usefulnessof an Accounting Information System forEffective Organizational Performance. International Journal of Economics and Finance; Vol. 4; p136-145.

Syahril, F. Mega dan Ventje Ilat. 2016. Evaluasi Efisiensi dan Efektifitas Pengelolaan Keuangan Daerah Pada Badan Pengelola Keuangan dan Barang Milik Daerah (BPKBMD) Kota Bitung. Fakultas Ekonomi dan Bisnis Universitas Sam Ratulangi Manado.

Tangkilisan, Hessel Nogi.S. 2004. Kebijakan dan Manajemen Otonomi Daerah.Yogyakarta:Penerbit Lukman Offset

Triandhini, Mia. 2018. Analisis Kesuksesan Implementasi Sistem Informasi Manajemen Keuangan Pemerintah Kabupaten Sukoharjo. Surakarta. Universitas Muhammadiyah Surakarta.

Wibowo. $2013 \quad$ Manajemen Kinerja, Jakarta:Rajawali Pers. 